02

\title{
Исследование строения, ионной, молекулярной подвижности и термических свойств гидратов пентафторидоцирконата аммония
}

\author{
() Е.И. Войт, А.Б. Слободюк, Н.А. Диденко \\ Институт химии Дальневосточного отделения РАН, \\ 690022 Владивосток, Россия \\ e-mail: evoit@ich.dvo.ru
}

Поступила в редакцию 09.08.2018 г.

\begin{abstract}
Методами ИК, КР, ЯМР $\left({ }^{1} \mathrm{H},{ }^{19} \mathrm{~F}\right.$, включая ВМУ $\left.{ }^{19} \mathrm{~F}\right)$, ТГ-ДТА исследовано влияние гидратного числа на изменение строения, термических свойств и характер ионной (молекулярной) подвижности в кристаллогидpaтax $\mathrm{NH}_{4} \mathrm{ZrF}_{5} \cdot \mathrm{H}_{2} \mathrm{O}, \mathrm{NH}_{4} \mathrm{ZrF}_{5} \cdot 0.75 \mathrm{H}_{2} \mathrm{O}$. Данными ИК, КР-спектроскопии подтверждены отличия структур кристаллогидратов: строение анионов, состояние молекул воды, прочность водородных связей О-Н.․ F, $\mathrm{N}-\mathrm{H} \cdots \mathrm{F}$. Методом ЯМР ВМУ ${ }^{19} \mathrm{~F}$ определены изотропные химические сдвиги магнитно-неэквивалентных позиций и соотнесены с кристаллическими структурами исследованных соединений. Установлено, что с отщеплением молекул воды из $\mathrm{NH}_{4} \mathrm{ZrF}_{5} \cdot \mathrm{H}_{2} \mathrm{O}$ и $\mathrm{NH}_{4} \mathrm{ZrF}_{5} \cdot 0.75 \mathrm{H}_{2} \mathrm{O}$ происходит трансформация цепочечной или слоистой структур, сопровождающаяся увеличением числа мостиковых связей с сохранением или повышением размерности структурного мотива аниона. По данным ЯМР ${ }^{1} \mathrm{H}$ диффузия катионов $\mathrm{NH}_{4}^{+}$имеет место только в $\mathrm{NH}_{4} \mathrm{ZrF}_{5}$ в интервале температур $370-520 \mathrm{~K}$.
\end{abstract}

DOI: $10.21883 /$ OS.2019.02.47196.233-18

\section{Введение}

К числу соединений с высокой ионной подвижностью и проводимостью могут быть отнесены фторидоцирконаты, характеризующиеся как цепочечным, так и островным строением комплексного аниона: $\left(\mathrm{NH}_{4}\right)_{2} \mathrm{ZrF}_{6}$, $\left(\mathrm{NH}_{4}\right)_{2-x} \mathrm{M}_{x} \mathrm{ZrF}_{6}\left(\mathrm{M}=\mathrm{K}^{+}, \mathrm{Rb}^{+}, x \sim 0.5\right),\left(\mathrm{NH}_{4}\right)_{3} \mathrm{ZrF}_{7}$, $\left(\mathrm{NH}_{4}\right)_{3-x} \mathrm{M}_{x} \mathrm{ZrF}_{7}\left(\mathrm{M}=\mathrm{Rb}^{+}, \mathrm{Cs}^{+}, x=0.3,0.25\right) \quad[1,2]$. $\mathrm{B}$ качестве внешнесферных катионов предпочтительны крупные высокополяризуемые катионы - такие, например, как аммоний. Дополнительное разупорядочение структуры может быть внесено путем частичного замещении части $\mathrm{NH}_{4}^{+}$другим одновалентным катионом $\left(\mathrm{K}^{+}\right.$, $\mathrm{Rb}^{+}, \mathrm{Cs}^{+}$) c сохранением „материнской“ аммонийной структуры.

В аспекте выявления взаимосвязи „состав-структурасвойство“ комплексные фториды циркония с отношением $\mathrm{F}: \mathrm{Zr}=5$ изучены значительно меньше гепта- и гексафторидоцирконатов с гомо- и гетеровалентной катионной подрешеткой [1-8]. Во фторидоцирконатах при отношении $\mathrm{F} / \mathrm{Zr}=5$ возможны два пути насыщения координационной емкости $\mathrm{Zr}(К Ч=8)$ : либо объединение $\mathrm{Zr}$-полиэдров через мостиковые атомы фтора с формированием слоистых структур, либо образование цепочечных структур вследствие дополнительной координации молекулярного лиганда $\mathrm{H}_{2} \mathrm{O}$. Структуры пентафторидои аквапентафторидоцирконатов в значительной мере зависят от природы внешнесферного катиона.

К настоящему времени известны два кристаллогидрата с катионом аммония, имеющие составы $\mathrm{NH}_{4} \mathrm{ZrF}_{5} \cdot \mathrm{H}_{2} \mathrm{O}$ и $\mathrm{NH}_{4} \mathrm{ZrF}_{5} \cdot 0.75 \mathrm{H}_{2} \mathrm{O}$. Указанные соединения относятся к числу разнолигандных комплексных соединений, в которых центральный атом $\mathrm{Zr}$ помимо F-лигандов координирован также молекулой воды.
Ранее моногидраты пентафторидоцирконатов получены также с катионами $\mathrm{K}^{+}, \mathrm{Na}^{+}, \mathrm{Rb}^{+}, \mathrm{Cs}^{+}, \mathrm{Tl}^{+}$[9]. В работах [10-12] приведены результаты исследования термической устойчивости и данные ИК спектров $\mathrm{MZrF}_{5} \cdot \mathrm{H}_{2} \mathrm{O}\left(\mathrm{M}=\mathrm{K}^{+}, \mathrm{Rb}^{+}, \mathrm{Cs}^{+}, \mathrm{NH}_{4}^{+}\right)$. Сравнивая структуры моногидратов $\mathrm{MZrF}_{5} \cdot \mathrm{H}_{2} \mathrm{O}\left(\mathrm{M}=\mathrm{K}^{+}, \mathrm{NH}_{4}^{+}\right)$и их безводных аналогов, можно сделать вывод, что при одном и том же отношении $\mathrm{F} / \mathrm{Zr}=5$ в комплексном анионе дополнительная координация циркония молекулой воды приводит к переходу от бесконечных слоев $\left[\mathrm{ZrF}_{5}\right]_{n}^{n-}$ к полимерным цепям $\left[\mathrm{ZrF}_{5}\left(\mathrm{H}_{2} \mathrm{O}\right)\right]_{n}^{n-}$. Различаются также конфигурации координационных полиэдров $\mathrm{Zr}$ (КП) в слоях и цепях и способы их сочленения.

С целью уточнения, дополнения, систематизации и обобщения данных о строении, термической стабильности гидратов пентафторидоцирконата аммония $\mathrm{NH}_{4} \mathrm{ZrF}_{5} \cdot \mathrm{H}_{2} \mathrm{O}, \mathrm{NH}_{4} \mathrm{ZrF}_{5} \cdot 0.75 \mathrm{H}_{2} \mathrm{O}$ и определения характера структурной трансформации при переходе от $\mathrm{NH}_{4} \mathrm{ZrF}_{5} \cdot n \mathrm{H}_{2} \mathrm{O} \rightarrow \mathrm{NH}_{4} \mathrm{ZrF}_{5}$ проведено их комплексное исследование методами колебательной спектроскопии, спектроскопии ЯМР (ЯМР ВМУ ${ }^{19} \mathrm{~F}$ ) и термического анализа. Совокупность полученных данных позволяет провести сравнительную оценку и сопоставить результаты с данными исследований строения, термического поведения $\left(\mathrm{NH}_{4}\right)_{2} \mathrm{ZrF}_{6}$ и характера его термического превращения в $\mathrm{NH}_{4} \mathrm{ZrF}_{5}$ [13].

\section{Экспериментальная часть}

Синтез соединений $\mathrm{NH}_{4} \mathrm{ZrF}_{5} \cdot \mathrm{H}_{2} \mathrm{O}$ и $\mathrm{NH}_{4} \mathrm{ZrF}_{5} \cdot 0.75 \mathrm{H}_{2} \mathrm{O}$ проведен из реакционной смеси $\mathrm{ZrO}\left(\mathrm{NO}_{3}\right)_{2} \cdot 2 \mathrm{H}_{2} \mathrm{O}$ и $\mathrm{NH}_{4} \mathrm{~F}$ (при мольном отношении $1: 2)$ в водном растворе фтористоводородной кислоты. 
Взаимодействие компонентов протекает в соответствии со схемой $\mathrm{ZrO}\left(\mathrm{NO}_{3}\right)_{2}+2 \mathrm{NH}_{4} \mathrm{~F}+3 \mathrm{HF} \rightarrow \mathrm{NH}_{4} \mathrm{ZrF}_{5}+$ $+\mathrm{NH}_{4} \mathrm{NO}_{3}+\mathrm{HNO}_{3}+\mathrm{H}_{2} \mathrm{O}$. При введении в систему $\mathrm{NH}_{4} \mathrm{~F}$ в виде насыщенного (либо разбавленного по объему в 5 раз) водного раствора при температуре синтеза осаждаемой фазой является соединение состава $\mathrm{NH}_{4} \mathrm{ZrF}_{5} \cdot 0.75 \mathrm{H}_{2} \mathrm{O}$ (либо из разбавленного раствора состава $\left.\mathrm{NH}_{4} \mathrm{ZrF}_{5} \cdot \mathrm{H}_{2} \mathrm{O}\right)$.

$5.34 \mathrm{~g}$ цирконила азотнокислого 2-водного (чда $\geq 99 \%$ ) $(0.02 \mathrm{~mol})$ растворено в смеси $10 \mathrm{ml} \mathrm{H}_{2} \mathrm{O}$ и $3 \mathrm{ml} \mathrm{40 \%} \mathrm{HF}$ (осч 99.99\%) при комнатной температуре. В полученный раствор добавлен водный раствор фторида аммония: $1.48 \mathrm{~g}(0.04 \mathrm{~mol})$ в $4 \mathrm{ml} \mathrm{H} \mathrm{H}_{2} \mathrm{O}$ либо в $20 \mathrm{ml} \mathrm{H} \mathrm{H}_{2} \mathrm{O}$. При температуре $10-12^{\circ} \mathrm{C}$ в холодильнике в течение $2 \mathrm{~h}$ (либо суток) из реакционной смеси образуется кристаллический осадок. Кристаллы отфильтрованы, промыты небольшим количеством воды со спиртом, высушены при комнатной температуре. Методика синтеза $\left(\mathrm{NH}_{4}\right)_{2} \mathrm{ZrF}_{6}$ описана в работе [13].

$\mathrm{NH}_{4} \mathrm{ZrF}_{5}$ получен методом термической дегидратации $\mathrm{NH}_{4} \mathrm{ZrF}_{5} \cdot \mathrm{H}_{2} \mathrm{O}$ при его нагревании на дериватографе со скоростью $5 \mathrm{deg} / \mathrm{min}$ до температуры $200^{\circ} \mathrm{C}$. Фазовый состав продуктов синтеза и их термического разложения был подтвержден методом рентгенофазового анализа (РФА), а строение охарактеризовано методами колебательной спектроскопии, спектроскопии ЯМР.

Регистрация КР-спектров исследуемых соединений проведена на спектрометре RFS100/S (лазер Nd:YAG, $\lambda=1064 \mathrm{~nm}$ ) с разрешением $4 \mathrm{~cm}^{-1}$. Инфракрасные спектры получены при комнатной температуре с использованием прибора Vertex 70 с образцов, подготовленных в виде суспензии в вазелиновом масле на стекле KRS-5, в области $4000-400 \mathrm{~cm}^{-1}$.

Спектры ЯМР $\left({ }^{19} \mathrm{~F},{ }^{1} \mathrm{H}\right)$ записаны на спектрометре Bruker Avance AV-300 в магнитном поле 7.05 Tl. Для регистрации спектров высокого разрешения использовано вращение образца под магическим углом (ВМУ) в роторе диаметром $4 \mathrm{~mm}$ с частотой $12-18 \mathrm{kHz}$ и методика спинового эха Хана, синхронизированного с периодом вращения образца. Изотропные сигналы ЯМР ${ }^{19} \mathrm{~F}$ выделяли сопоставлением спектров, полученных при различных частотах вращения. В качестве эталона химического сдвига (XC) ${ }^{19} \mathrm{~F}$ использовали $\mathrm{CFCl}_{3},{ }^{1} \mathrm{H}-$ тетраметилсилан.

Термические исследования образцов проведены на дериватографе Q-1000 МОМ при скорости нагревания $5 \mathrm{deg} / \mathrm{min}$. Навески составляли $100 \mathrm{mg}$. В качестве эталона использован прокаленный $\mathrm{Al}_{2} \mathrm{O}_{3}$.

\section{Результаты и их обсуждение}

$\left(\mathrm{NH}_{4}\right)_{2} \mathrm{ZrF}_{6}$ кристаллизуется в ромбической сингонии с параметрами элементарной ячейки $a=13.398(8)$, $b=7.739(3), c=11.680(4) \AA$, пространственная группа Pca2 $_{1}, Z=8$. Кристаллическая структура $\left(\mathrm{NH}_{4}\right)_{2} \mathrm{ZrF}_{6}$ образована из бесконечных цепей и катионов аммония, распределенных вокруг этих цепей $[14,15]$. В данном сообщении для наглядности представлен фрагмент его структуры (рис. 1,a).

$\mathrm{NH}_{4} \mathrm{ZrF}_{5} \cdot \mathrm{H}_{2} \mathrm{O}$ кристаллизуется в моноклинной сингонии с параметрами элементарной ячейки $a=10.723(2)$, $b=7.529(1), c=6.761(1) \AA, \beta=78.24(2)^{\circ}$, пространственная группа $P 2_{1} / n, Z=4$. Согласно структурным данным, кристаллическая структура $\mathrm{NH}_{4} \mathrm{ZrF}_{5} \cdot \mathrm{H}_{2} \mathrm{O}$ [16] состоит из полимерных анионных цепей $\left[\mathrm{ZrF}_{5}\left(\mathrm{H}_{2} \mathrm{O}\right)\right]_{n}^{n-}$ и расположенных между ними катионов $\mathrm{NH}_{4}^{+}$(рис. $\left.1, b\right)$. Полимерные цепи образованы из объединенных общими ребрами $\mathrm{Zr}\langle 2 \mathrm{~F}\rangle \mathrm{Zr}$ полиэдров $\left[\mathrm{ZrF}_{7}\left(\mathrm{H}_{2} \mathrm{O}\right)\right]$. В КП $\mathrm{Zr}$ длины концевых связей $\mathrm{Zr}-\mathrm{F}$ равны $2.010(4), 2.033(4)$ и 2.059(4) $\AA$, а длины мостиковых связей лежат в интервале 2.088(4)-2.249(4) А̊. Расстояние $\mathrm{Zr}-\mathrm{O}$ до атома кислорода координированной $\mathrm{H}_{2} \mathrm{O}$ равно 2.261(6) А̊. Координированная молекула воды участвует в образовании двух сравнительно прочных водородных связей (ВС)

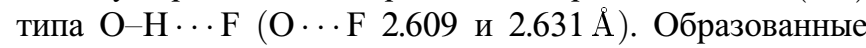
катионом аммония ВC N-H ‥ F более слабые (расстояние $\mathrm{N}$. . . F 2.839-3.129 ̊).

В полимерных структурах фторидоцирконатов присутствуют два типа атомов фтора - концевые $\left(\mathrm{F}_{\mathrm{K}}\right)$ и мостиковые $\left(\mathrm{F}_{\mathrm{M}}\right)$. Сравнивая цепочечные структуры $\mathrm{NH}_{4} \mathrm{ZrF}_{5} \cdot \mathrm{H}_{2} \mathrm{O}$ и $\left(\mathrm{NH}_{4}\right)_{2} \mathrm{ZrF}_{6}$, формально фрагменты $\left[\mathrm{ZrF}_{7}\left(\mathrm{H}_{2} \mathrm{O}\right)\right]$ в комплексном анионе кристаллогидрата можно получить заменой концевого F-лиганда в полиэдpe $\left[\mathrm{ZrF}_{8}\right]$ структуры $\left(\mathrm{NH}_{4}\right)_{2} \mathrm{ZrF}_{6}$ на терминальную молекулу $\mathrm{H}_{2} \mathrm{O}$ при сохранении КЧ $\mathrm{Zr}=8$. Однако описанная замена влечет за собой изменение в характере ассоциации структурных фрагментов: в решетке $\mathrm{NH}_{4} \mathrm{ZrF}_{5} \cdot \mathrm{H}_{2} \mathrm{O}$ цепи формируются сочленением полиэдров $\left[\mathrm{ZrF}_{7}\left(\mathrm{H}_{2} \mathrm{O}\right)\right]$ посредством общих ребер, в итоге в $\mathrm{Zr}$-полиэдре имеются $4 \mathrm{~F}_{\mathrm{M}}, 3 \mathrm{~F}_{\mathrm{\kappa}}$ и $1 \mathrm{H}_{2} \mathrm{O}$. А в структуре $\left(\mathrm{NH}_{4}\right)_{2} \mathrm{ZrF}_{6} \mathrm{KП} \mathrm{Zr}$ объединяются попеременно общей треугольной гранью и общей вершиной $\left(4 \mathrm{~F}_{\mathrm{M}}\right.$ и $\left.4 \mathrm{~F}_{\mathrm{\kappa}}\right)$ (рис. $\left.1, a\right)[15]$.

Присутствие в анионе кристаллогидрата $\mathrm{NH}_{4} \mathrm{ZrF}_{5} \cdot \mathrm{H}_{2} \mathrm{O}$ дополнительного протонодонорного лиганда $\mathrm{H}_{2} \mathrm{O}$ вызывает сшивание $\mathrm{Zr}$-полиэдров из соседних полимерных цепей посредством сравнительно прочных ВC $\mathrm{O}-\mathrm{H} \cdots \mathrm{F}$ (полимерный „псевдослой“). Строение $\mathrm{NH}_{4} \mathrm{ZrF}_{5} \cdot \mathrm{H}_{2} \mathrm{O}$ можно рассматривать как структуру переходного состояния от $\left(\mathrm{NH}_{4}\right)_{2} \mathrm{ZrF}_{6}$, в котором цепь $\mathrm{Zr}$-полиэдров (,анионный канал“) окружена со всех сторон внешнесферными катионами $\mathrm{NH}_{4}^{+}$, к структуре $\mathrm{NH}_{4} \mathrm{ZrF}_{5}-$ с чередованием слоев из $\mathrm{Zr}$-полиэдров и прослоек катионов.

\section{ИК, КР-спектроскопия, ТГ-ДТА}

Указанные отличия строения соединений $\left(\mathrm{NH}_{4}\right)_{2} \mathrm{ZrF}_{6}$, $\mathrm{NH}_{4} \mathrm{ZrF}_{5} \cdot \mathrm{H}_{2} \mathrm{O}$ находят отражение в колебательных спектрах (рис. 2).

$\left(\mathbf{N H}_{4}\right)_{2} \mathbf{Z r F}_{6}$. Известно, что полосы валентных колебаний катионов $\mathrm{NH}_{4}^{+}$(симметрии $\mathrm{Td}$ ) находятся в области 

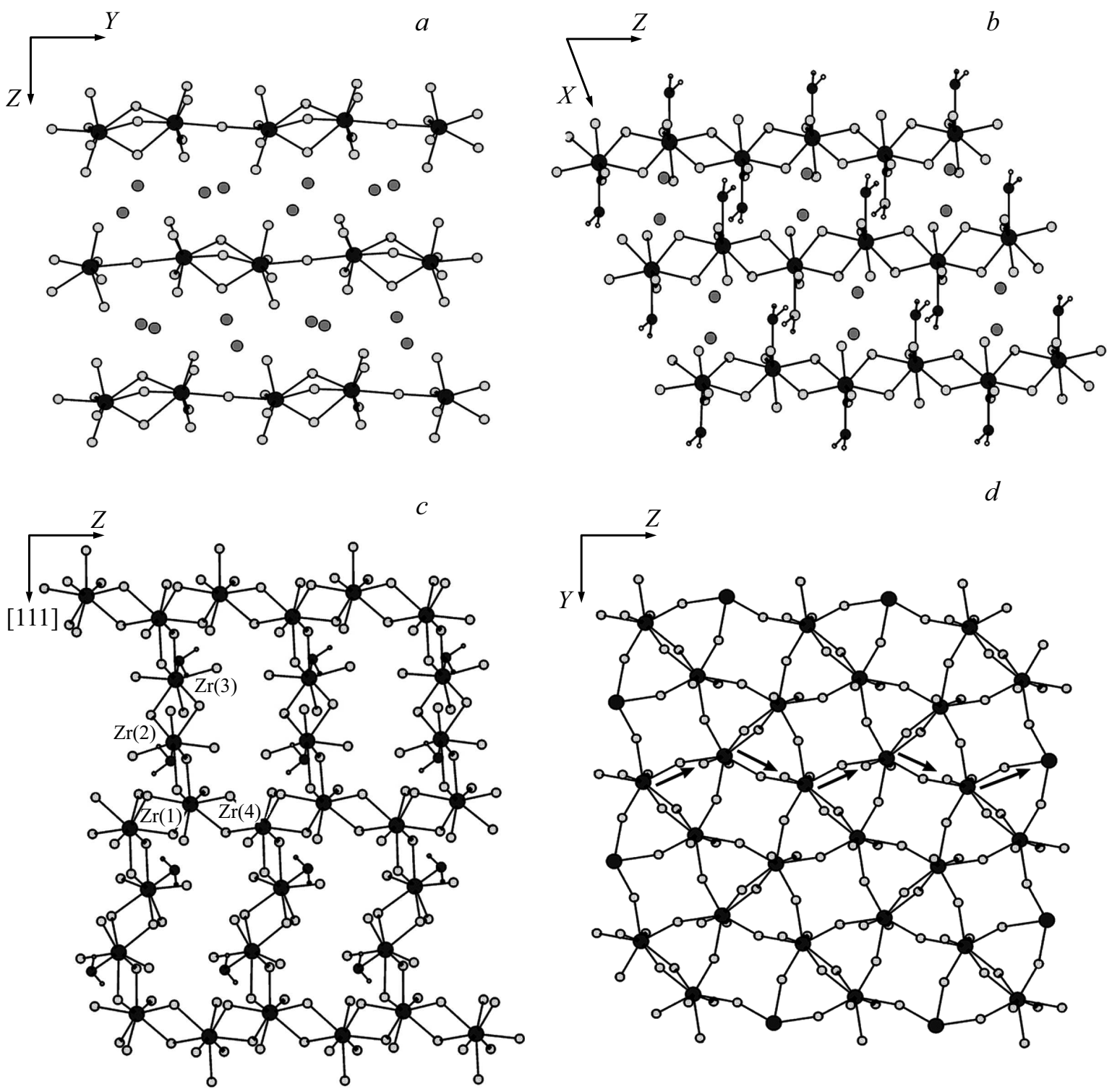

$\mathrm{Zr} \circ \mathrm{F} \bigodot_{\mathrm{H}_{2} \mathrm{O}} \mathrm{N}$

Рис. 1. Фрагменты кристаллических структур соединений: (a) $\left(\mathrm{NH}_{4}\right)_{2} \mathrm{ZrF}_{6},(b) \mathrm{NH}_{4} \mathrm{ZrF}_{5} \cdot \mathrm{H}_{2} \mathrm{O},(c) \mathrm{NH}_{4} \mathrm{ZrF}_{5} \cdot 0.75 \mathrm{H}_{2} \mathrm{O},(d) \mathrm{NH}_{4} \mathrm{ZrF}_{5}$.

$3000-3250 \mathrm{~cm}^{-1}\left(v_{3}, v_{1}, v_{2}+v_{4}\right)$, деформационных колебаний - в области 1700 и $1400 \mathrm{~cm}^{-1}\left(v_{2}, v_{4}+v_{6}, v_{4}\right)$. В структуре гексафторидоцирконата аммония катионы $\mathrm{NH}_{4}^{+}$занимают две позиции, кроме того, их симметрия снижена вследствие взаимодействия с анионом. И уже при комнатной температуре наблюдаются реориентации и изотропное вращение катионов $\mathrm{NH}_{4}^{+}$[1]. В связи с этим в ИК спектре $\left(\mathrm{NH}_{4}\right)_{2} \mathrm{ZrF}_{6}$ не проявляется расщепление валентных колебаний $v_{3}, v_{1}$ на отдельные компоненты. Полосы 3220 и $3088 \mathrm{~cm}^{-1}$ можно отнести к колебаниям $v_{3}, v_{2}+v_{4}$, а полосу деформационных колебаний $1423 \mathrm{~cm}^{-1}-$ к $v_{4}$ (рис. 2,a). Вследствие динамических движений катионов и переключения ВС составные колебания, зависящие от сил ВС $v_{4}+v_{6}$ $\left(1779,1669 \mathrm{~cm}^{-1}\right)$ и $v_{2}+v_{6}\left(2049 \mathrm{~cm}^{-1}\right)$, мало интенсивны [13].

Анализ спектров ниже $600 \mathrm{~cm}^{-1}$ может дать дополнительную информацию о изменении строения фторидоцирконатного аниона. В КР-спектре $\left(\mathrm{NH}_{4}\right)_{2} \mathrm{ZrF}_{6}$ в области колебаний фторидоцирконатного аниона наблюдаются широкие полосы с максимумами 537, 472, 360-330 и $221 \mathrm{~cm}^{-1}$ (рис. 2,a). Учитывая стехиометрию $\mathrm{F} / \mathrm{Zr}=6$, наиболее интенсивную полосу при $537 \mathrm{~cm}^{-1}$ следует отнести к полносимметричному колебанию $v_{s} \mathrm{Zr}-\mathrm{F}_{\text {к }}$ димерной группы $\mathrm{Zr}_{2} \mathrm{~F}_{12}^{4-}$ симметрии $C_{2 v}$. Слабая по интенсивности полоса при $472 \mathrm{~cm}^{-1}$ относится к близким по частотам и перекрывающимся симметричным комбинациям валентных колебаний $v_{\mathrm{as}} \mathrm{Zr}-\mathrm{F}_{\text {к }}$, а асим- 

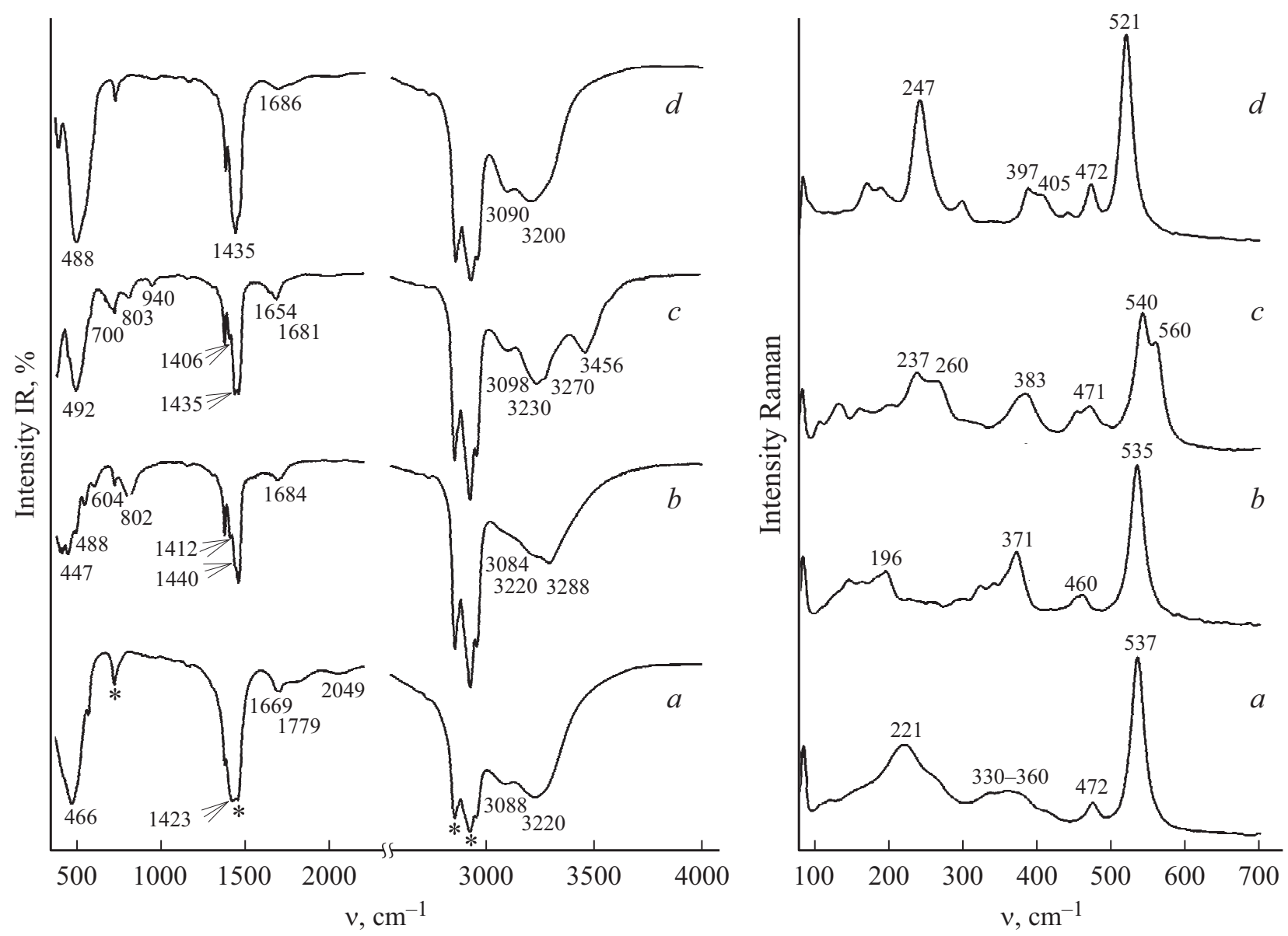

Рис. 2. ИК, КР-спектры соединений: (a) $\left(\mathrm{NH}_{4}\right)_{2} \mathrm{ZrF}_{6},(b) \mathrm{NH}_{4} \mathrm{ZrF}_{5} \cdot \mathrm{H}_{2} \mathrm{O},(c) \mathrm{NH}_{4} \mathrm{ZrF}_{5} \cdot 0.75 \mathrm{H}_{2} \mathrm{O},(d) \gamma-\mathrm{NH}_{4} \mathrm{ZrF}_{5}$.

метричные комбинации колебаний $v_{\mathrm{as}} \mathrm{Zr}-\mathrm{F}_{\mathrm{\kappa}}$ наиболее интенсивны в ИК спектре, им соответствует полоса с максимумом при $466 \mathrm{~cm}^{-1}$. Наибольший вклад в КРполосу при $360-330 \mathrm{~cm}^{-1}$ вносит полносимметричное валентное колебание $v_{s} \mathrm{Zr}-\mathrm{F}_{\mathrm{M}}(\mathrm{A} 1)$, включающее движение мостиковых атомов F. В область $330-300 \mathrm{~cm}^{-1}$ попадают также всевозможные деформационные колебания $\delta \mathrm{ZrF}_{n}$ (где $n=\mathrm{KЧ} \mathrm{Zr}$ ) с участием мостиковых связей в КП $\left[\mathrm{ZrF}_{8}\right]$. Наличие двух типов мостиковых связей в структуре $\left(\mathrm{NH}_{4}\right)_{2} \mathrm{ZrF}_{6}$ приводит к дополнительному уширению деформационной полосы. Наиболее интенсивная полоса с максимумом при $221 \mathrm{~cm}^{-1}$ соответствует ножничному колебанию с участием концевых связей $\delta_{\mathrm{sc}} \mathrm{ZrF}_{n}(\mathrm{~A} 1)$.

$\mathbf{N H}_{4} \mathbf{Z r F}_{5} \cdot \mathbf{H}_{2}$ O. В ИК спектре $\mathrm{NH}_{4} \mathrm{ZrF}_{5} \cdot \mathrm{H}_{2} \mathrm{O}$ (рис. 2,b) в области валентных колебаний катионов $\mathrm{NH}_{4}^{+}$появляется заметный максимум, сдвинутый в область высоких частот до $3288 \mathrm{~cm}^{-1}$, который, вероятно, относится к колебаниям $v \mathrm{OH}$, включенных

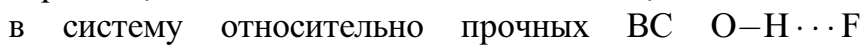
(расстояние $\mathrm{O} \cdots \mathrm{F} \quad 2.609$ и $2.631 \AA \AA$ ). В области деформационных колебаний молекул $\mathrm{H}_{2} \mathrm{O}$ на фоне составных аммонийных колебаний растет интенсивность полосы с максимумом при $1683 \mathrm{~cm}^{-1}$, что также связано с присутствием молекул $\mathrm{H}_{2} \mathrm{O}$ в структуре. Колебания $v_{4}$ катионов $\mathrm{NH}_{4}^{+}$проявляются двумя максимумами (1412 с плечом $1440 \mathrm{~cm}^{-1}$ ), что подтверждает снижение симметрии аммонийных групп под действием ВС $(\mathrm{N} \cdots \mathrm{F} \quad 2.839-3.129 \AA)$. В области либрационных колебаний молекул $\mathrm{H}_{2} \mathrm{O}$ присутствуют две полосы с максимумами $\sim 802$ и $604 \mathrm{~cm}^{-1}$, которые характерны веерным и маятниковым колебаниям молекул $\mathrm{H}_{2} \mathrm{O}$ и проявляются в спектре лишь при образовании сильных ВС.

В КР-спектре $\mathrm{NH}_{4} \mathrm{ZrF}_{5} \cdot \mathrm{H}_{2} \mathrm{O}$ полоса $v_{s} \mathrm{Zr}-\mathrm{F}_{\mathrm{K}}$ практически не меняет своего положения, подтверждая сохранение КЧ $\mathrm{Zr}$ и строение анионного мотива. В то же время полоса колебаний $v_{s} \mathrm{Zr}-\mathrm{F}_{\mathrm{M}}$ становится более интенсивной и имеет выраженный максимум при $371 \mathrm{~cm}^{-1}$, что согласуется с образованием односортных реберных мостиковых связей в анионной подрешетке. Слабая интенсивность деформационных полос $\delta \mathrm{ZrF}_{n}$, вероятно, обусловлена влиянием относительно сильных BC O-H $\cdots$ F на атомы F.

Усложненный характер (ряд максимумов 543, 488, $447,412 \mathrm{~cm}^{-1}$ ) широкой интенсивной валентной полосы в ИК спектре $\mathrm{NH}_{4} \mathrm{ZrF}_{5} \cdot \mathrm{H}_{2} \mathrm{O}$ связан с влиянием протонодонорного лиганда $\mathrm{H}_{2} \mathrm{O}$ на анион и соответственно 
с изменением дипольного момента его структурной единицы.

Разное строение рассматриваемых соединений $\mathrm{NH}_{4} \mathrm{ZrF}_{5} \cdot \mathrm{H}_{2} \mathrm{O}$ и $\left(\mathrm{NH}_{4}\right)_{2} \mathrm{ZrF}_{6}$ должно отразиться на их устойчивости при повышении температуры. Как было установлено ранее [13], нагревание гексафторидоцирконата аммония приводит к фазовому переходу $\left(T=140^{\circ} \mathrm{C}\right)$ с образованием термически лабильной фазы, в которой наблюдается диффузия ионов аммония и фтора. Процесс разложения $\left(\mathrm{NH}_{4}\right)_{2} \mathrm{ZrF}_{6}$ (орторомбический) до $\mathrm{NH}_{4} \mathrm{ZrF}_{5}$ (моноклинный) является двухстадийным. На первой стадии разложения $\left(T=140-240^{\circ} \mathrm{C}\right), \quad$ начало которой инициировано фазовым переходом $\alpha \rightarrow \beta$, происходит образование фаз нестехиометрического состава $\left(\mathrm{NH}_{4}\right)_{2-x} \mathrm{ZrF}_{6-x}$, в которых значение $x$ стремится к значению 0.25 . Можно предположить, что указанные фазы имеют цепочечную структуру, в которой реализуется два способа объединения Zr-полиэдров: . . - -ребро-ребро-. . и …-ребро-вершина-ребро-.... То есть в цепочечной структуре наряду с восьмикоординационными присутствуют и семикоординационные полиэдры $\mathrm{Zr}$. Подобное строение полимерных $\mathrm{Zr}$-цепей найдено в кристаллической структуре фторидоцирконата нестехиометрического состава $\mathrm{Cs}_{1+x}\left(\mathrm{H}_{2} \mathrm{O}\right)_{1-x} \mathrm{MgZr}_{2} \mathrm{~F}_{11+x} \cdot 2 \mathrm{H}_{2} \mathrm{O}$ $(x=0.73)$ [17], а также в структуре $\mathrm{Li}\left(\mathrm{NH}_{4}\right)_{6} \mathrm{Zr}_{4} \mathrm{~F}_{23}$ [18]. На второй стадии при образовании $\mathrm{NH}_{4} \mathrm{ZrF}_{5}$ из фазы $\quad\left(\mathrm{NH}_{4}\right)_{2-x} \mathrm{ZrF}_{6-x} \quad(x=0.25) \quad\left(T=240-310^{\circ} \mathrm{C}\right)$ происходит трансформация цепочечной структуры в слоистую. Таким образом, в процессе термической диссоциации $\left(\mathrm{NH}_{4}\right)_{2} \mathrm{ZrF}_{6}$ при температуре выше $140^{\circ} \mathrm{C}$ уменьшается отношение $\mathrm{F} / \mathrm{Zr}$, NH4/Zr и КЧ $\mathrm{Zr}$, что приводит в итоге к трансформации цепочечной структуры в слоистую с образованием $\gamma-\mathrm{NH}_{4} \mathrm{ZrF}_{5}$.

Термическое разложение $\mathrm{NH}_{4} \mathrm{ZrF}_{5} \cdot \mathrm{H}_{2} \mathrm{O}$ на первой стадии связано с дегидратацией соединения. Процесс начинается при $80^{\circ} \mathrm{C}$, протекает в одну стадию с максимальной скоростью при $90^{\circ} \mathrm{C}$ и характеризуется на кривой ДТА узким интенсивным эндотермическим эффектом, что согласуется с данными [11]. Убыль массы при $160^{\circ} \mathrm{C}$ составляет $8.0 \% \quad\left(\Delta m_{\text {расч }}=8.11 \%\right)$. Продуктом разложения по данным РФА является $\gamma-\mathrm{NH}_{4} \mathrm{ZrF}_{5}$. Таким образом, в случае $\mathrm{NH}_{4} \mathrm{ZrF}_{5} \cdot \mathrm{H}_{2} \mathrm{O}$ переход цепочечной структуры в слоистую протекает при более низких температурах.

$\mathbf{N H}_{4} \mathbf{Z r F}_{5} \cdot 0.75 \mathbf{H}_{2}$ O. В состав другого структурно исследованного соединения, аквапентафторидоцирконата аммония $\mathrm{NH}_{4} \mathrm{ZrF}_{5} \cdot 0.75 \mathrm{H}_{2} \mathrm{O}$, входит необычное количество молекул $\mathrm{H}_{2} \mathrm{O}$. В отличие от $\mathrm{NH}_{4} \mathrm{ZrF}_{5} \cdot \mathrm{H}_{2} \mathrm{O}$ в структуре $\mathrm{NH}_{4} \mathrm{ZrF}_{5} \cdot 0.75 \mathrm{H}_{2} \mathrm{O}$ имеется два сорта молекул $\mathrm{H}_{2} \mathrm{O}$ : кристаллизационные и координационные, что более наглядно отображается общей формулой $\left(\left(\mathrm{NH}_{4}\right)_{4}\left[\mathrm{Zr}_{4} \mathrm{~F}_{20}\left(\mathrm{H}_{2} \mathrm{O}\right)_{2}\right] \cdot \mathrm{H}_{2} \mathrm{O}\right)$. Другой структурной особенностью соединения $\mathrm{NH}_{4} \mathrm{ZrF}_{5} \cdot 0.75 \mathrm{H}_{2} \mathrm{O}$ является то, что в комплексном анионе только в $1 / 2$ части КП $\mathrm{Zr}$ содержатся молекулы $\mathrm{H}_{2} \mathrm{O}$. Соединение кристаллизуется в моноклинной сингонии с параметра- ми элементарной ячейки $a=23.013(3), b=15.158(3)$, $c=6.721(1) \AA, \gamma=118.76(2)^{\circ}$, пространственная группа $B b, Z=16$ [19]. Основу кристаллической структуры кристаллогидрата $\mathrm{NH}_{4} \mathrm{ZrF}_{5} \cdot 0.75 \mathrm{H}_{2} \mathrm{O}$ составляют бесконечные слои $\left[\mathrm{Zr}_{4} \mathrm{~F}_{20}\left(\mathrm{H}_{2} \mathrm{O}\right)_{2}\right]_{n}^{4 n-}$ (рис. 1,c). Слои в структуре стоят из вытянутых вдоль оси $z$ цепей реберносвязанных КП $\left[\mathrm{ZrF}_{8}\right]$. Полимерные цепи связаны друг с другом димерными группами $\left[\mathrm{Zr}_{2} \mathrm{~F}_{12}\left(\mathrm{H}_{2} \mathrm{O}\right)_{2}\right.$ через общее ребро с образованием десятичленных металлоциклов. Полимерные цепи связаны друг с другом димерными группами $\left[\mathrm{Zr}_{2} \mathrm{~F}_{12}\left(\mathrm{H}_{2} \mathrm{O}\right)_{2}\right]$ в слои через общее ребро. Полиэдры $\left[\mathrm{ZrF}_{8}\right]$ и $\left[\mathrm{ZrF}_{7} \mathrm{OH}_{2}\right]$ содержат соответственно по два или три концевых атома фтора, расположенных на расстояниях около $2 \AA$. Каждый атом $\mathrm{Zr}$ биполиэдра включает координированную молекулу $\mathrm{H}_{2} \mathrm{O}$ (расстояние $\mathrm{Zr}-\mathrm{O}$ равно 2.35 и $2.36 \AA)$. Между слоями анионов $\left[\mathrm{Zr}_{4} \mathrm{~F}_{20}\left(\mathrm{H}_{2} \mathrm{O}\right)_{2}\right]_{n}^{4 n-}$ расположены катионы $\mathrm{NH}_{4}^{+}$и молекулы кристаллизационной воды, которые связывают соседние слои ВC $\mathrm{N}-\mathrm{H} \cdots \mathrm{F}$ и $\mathrm{O}-\mathrm{H} \cdots \mathrm{F}$ наряду с электростатическим взаимодействием.

По сравнению со спектрами $\mathrm{NH}_{4} \mathrm{ZrF}_{5} \cdot \mathrm{H}_{2} \mathrm{O}$ в ИК спектре $\mathrm{NH}_{4} \mathrm{ZrF}_{5} \cdot 0.75 \mathrm{H}_{2} \mathrm{O}$ в области валентных колебаний $\mathrm{NH}_{4}^{+}$видны значительные изменения (рис. 2,c). Проявляется полоса $3456 \mathrm{~cm}^{-1}$ с плечом при $3270 \mathrm{~cm}^{-1}$, которые можно отнести к $v \mathrm{OH} \cdots$. F кристаллизационной и координационной $\mathrm{H}_{2} \mathrm{O}$ соответственно. Неэквивалентность молекул воды в структуре $\mathrm{NH}_{4} \mathrm{ZrF}_{5} \cdot 0.75 \mathrm{H}_{2} \mathrm{O}$ также подтверждается наличием двух деформационных полос $\delta \mathrm{H}_{2} \mathrm{O}\left(1681\right.$ и $\left.1654 \mathrm{~cm}^{-1}\right)$. Появление полос либрационных колебаний $\left(940,803,700 \mathrm{~cm}^{-1}\right)$ доказывает участие молекул $\mathrm{H}_{2} \mathrm{O}$ в сильных ВС. Перемещение полосы $v_{4}$ до $1435 \mathrm{~cm}^{-1}$, относящейся к колебанию $\delta \mathrm{NH}_{4}$, говорит об упрочнении ВС.

В КР-спектре (рис. 2,c) образование более полимеризованной слоистой аквафторидной структуры в $\mathrm{NH}_{4} \mathrm{ZrF}_{5} \cdot 0.75 \mathrm{H}_{2} \mathrm{O}$ проявляется возникновением двух максимумов у валентной $v_{s} \mathrm{Zr}-\mathrm{F}_{\mathrm{K}}\left(540\right.$ и $\left.560 \mathrm{~cm}^{-1}\right)$ и деформационной полосы $\delta \mathrm{FZrF}\left(260\right.$ и $\left.237 \mathrm{~cm}^{-1}\right)$, что согласуется с наличием в структуре двух заметно отличающихся типов локального окружения Zr. K первому можно отнести КП атомов $\operatorname{Zr}(1)$ и $\operatorname{Zr}(4)$, образующих фтороцирконатные цепи, а ко второму - КП атомов $\operatorname{Zr}(2)$ и $\operatorname{Zr}(3)$, связанных в димерную группу $\left(4 \mathrm{~F}_{\mathrm{M}}, 3 \mathrm{~F}_{\mathrm{K}}\right.$ и $\mathrm{H}_{2} \mathrm{O}$ ) (рис. $\left.1, c\right)$. Уширенный контур полосы колебания $v_{s} \mathrm{Zr}-\mathrm{F}_{\mathrm{M}}$ с максимумом при $383 \mathrm{~cm}^{-1}$ отвечает разбросу длин реберных мостиковых связей $\mathrm{Zr}-\mathrm{F}_{\mathrm{M}}$ в структуре $\mathrm{NH}_{4} \mathrm{ZrF}_{5} \cdot 0.75 \mathrm{H}_{2} \mathrm{O}$.

В ИК спектре $\mathrm{NH}_{4} \mathrm{ZrF}_{5} \cdot 0.75 \mathrm{H}_{2} \mathrm{O}$ присутствует широкая полоса $492 \mathrm{~cm}^{-1}$, соответствующая колебаниям $v_{\mathrm{as}} \mathrm{Zr}-\mathrm{F}_{\mathrm{\kappa}}$ в анионе, ее положение по сравнению с положением в спектре $\left(\mathrm{NH}_{4}\right) \mathrm{ZrF}_{6}$ свидетельствует об общем снижении заряда аниона.

Термическая дегидратация $\left(\mathrm{NH}_{4}\right) \mathrm{ZrF}_{5} \cdot 0.75 \mathrm{H}_{2} \mathrm{O}$ протекает также в одну стадию в температурном интервале $90-170^{\circ} \mathrm{C}$ (с максимальной скоростью при $\left.110^{\circ} \mathrm{C}\right)$ и характеризуется уширенным эндоэффектом на кривой ДТА. Принимая во внимание структуру 
$\mathrm{NH}_{4} \mathrm{ZrF}_{5} \cdot 0.75 \mathrm{H}_{2} \mathrm{O}$, можно полагать, что при нагревании этого соединения первой должна удаляться кристаллизационная молекула воды. Разрушение системы ВС приводит к структурной перестройке с удалением еще двух молекул $\mathrm{H}_{2} \mathrm{O}$ из координационной сферы циркония. Убыль массы при температуре $160^{\circ} \mathrm{C}$ составляет $6.5 \%$ $\left(\Delta m_{\text {расч }}=6.21 \%\right)$. Продуктом разложения по данным РФА является $\gamma-\mathrm{NH}_{4} \mathrm{ZrF}_{5}$, кристаллизующийся в моноклинной сингонии с параметрами элементарной ячейки $a=7.973(9), b=7.923(7), c=7.911(7) \AA, \gamma=121.68^{\circ}$, пространственная группа $P 2_{1} / b, Z=4$. Структура моноклинной модификации $\gamma-\mathrm{NH}_{4} \mathrm{ZrF}_{5}$ слоистая [20]. Двумерная сетчатая структура состоит из бесконечных связанных вершинами биполиэдров $\left[\mathrm{Zr}_{2} \mathrm{~F}_{14}\right]$. В биполиэдре КП $\left[\mathrm{ZrF}_{8}\right]$ связаны реберной связью (рис. 1, $d$ ). Аналогичный способ соединения полиэдров встречается также в структурах $\mathrm{BaZr}_{2} \mathrm{~F}_{10} \cdot 2 \mathrm{H}_{2} \mathrm{O}$ и $\mathrm{TlZrF}_{5}[21,22]$.

По сравнению с гекса- и аквапентафторидоцирконатом BC $\mathrm{NH} \cdots \mathrm{F}$ в $\gamma-\mathrm{NH}_{4} \mathrm{ZrF}_{5}$ упрочнены, так как в его ИК спектре $v_{3}$ и $v_{4}\left(3200 \mathrm{~cm}^{-1}, 1435 \mathrm{~cm}^{-1}\right)$ сдвинуты в низко- и высокочастотную область соответственно (рис. 2,d). Также уменьшение содержания аммонийных групп в $\gamma-\mathrm{NH}_{4} \mathrm{ZrF}_{5}$ сказывается на снижении интенсивности составных полос $v_{4}+v_{6}, v_{2}+v_{6}$.

В КР-спектре $\gamma-\mathrm{NH}_{4} \mathrm{ZrF}_{5}$ в области колебаний фторидоцирконатного аниона заметен сдвиг полосы $v_{\mathrm{s}} \mathrm{Zr}-\mathrm{F}_{\text {к }}$ до $521 \mathrm{~cm}^{-1}$ и $v_{s} \mathrm{Zr}-\mathrm{F}_{\mathrm{м}}$ до 405 и $397 \mathrm{~cm}^{-1}$ вследствие возрастания степени полимеризации и упрочнения мостиковых связей в сравнении с гидратами (рис. 2,d). Максимальное различие расстояний в КП Zr, характеризующее степень их искажения, убывает при переходе от $\left(\mathrm{NH}_{4}\right)_{2} \mathrm{ZrF}_{6}$ к $\mathrm{NH}_{4} \mathrm{ZrF}_{5}$. Упорядочивание аниона и повышение локальной симметрии окружения атомов $\mathrm{Zr}$ в структуре пентафторидоцирконата приводит к сужению полосы деформационных колебаний и образованию четко выраженного максимума $\delta_{\mathrm{sc}} \mathrm{ZrFn}$ при $247 \mathrm{~cm}^{-1}$. Указанные изменения в спектрах находятся в соответствии со структурными данными [20].

Термическое разложение на воздухе безводной фазы $\gamma-\mathrm{NH}_{4} \mathrm{ZrF}_{5}$, полученной при дегидратации кристаллогидратов пентафторидоцирконата, начинается с заметной скоростью уже при $240^{\circ} \mathrm{C}$ с последовательным образованием продуктов состава $\left(\mathrm{NH}_{4}\right)_{2} \mathrm{Zr}_{3} \mathrm{OF}_{12} \rightarrow$ $\rightarrow\left(\mathrm{NH}_{4}\right) \mathrm{Zr}_{3} \mathrm{O}_{2} \mathrm{~F}_{9} \rightarrow \mathrm{Zr}_{7} \mathrm{O}_{9} \mathrm{~F}_{10} \rightarrow \mathrm{ZrO}_{2}$, исследованных ранее в работе [13].

\section{ЯМР исследование}

Наряду с типом координации фтора (мостиковый или концевой) положения сигналов в ЯМР ${ }^{19} \mathrm{~F}$ спектрах комплексных фторидоцирконатов будут коррелировать с длинами образующихся связей $\mathrm{Zr}-\mathrm{F}$. В целом можно ожидать, что сигналы ЯМР ${ }^{19} \mathrm{~F}$ фтора, связанного мостиковой связью, будут расположены в относительно сильном магнитном поле, и будут характеризоваться слабой

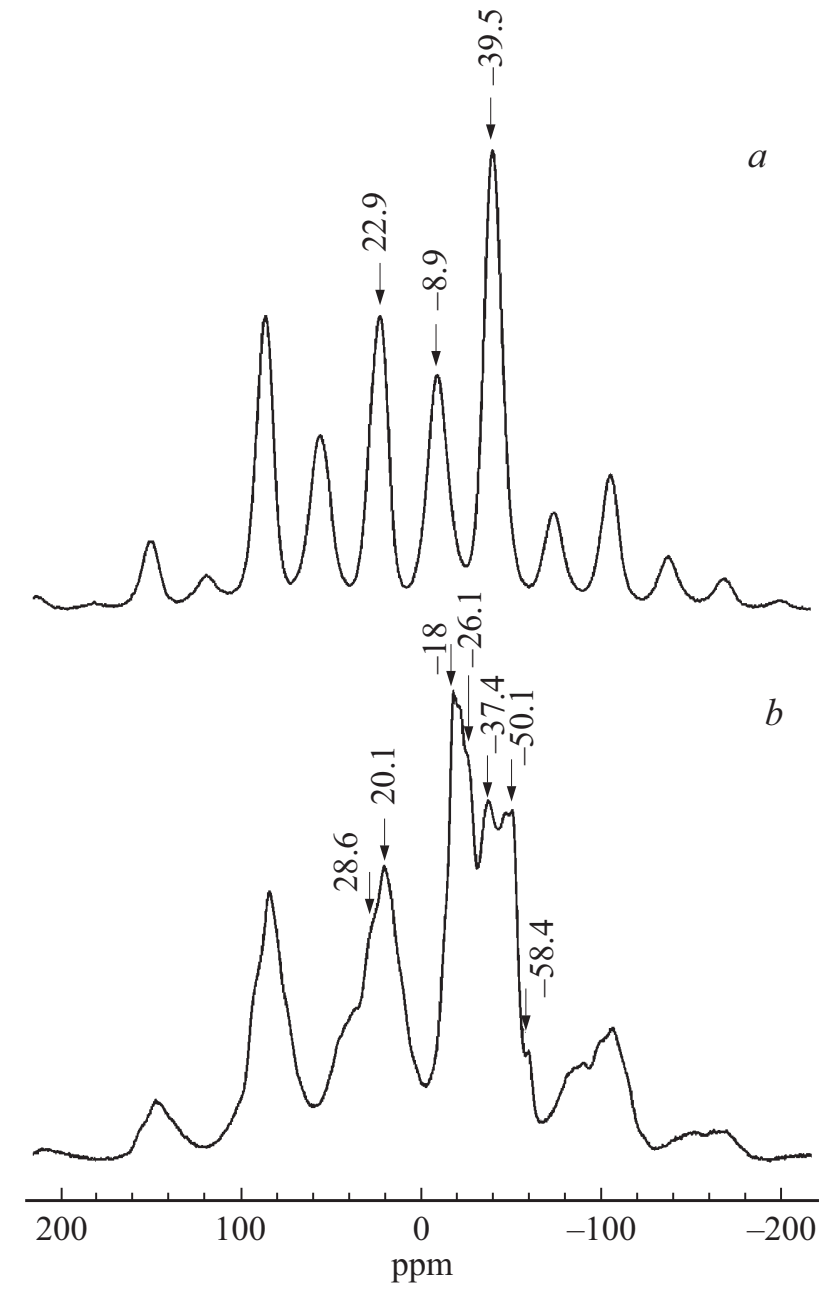

Рис. 3. Спектры ЯМР ВМУ ${ }^{19} \mathrm{~F}: \quad$ (a) $\quad \gamma-\mathrm{NH}_{4} \mathrm{ZrF}_{5} \quad$ и (b) $\mathrm{NH}_{4} \mathrm{ZrF}_{5} \cdot 0.75 \mathrm{H}_{2} \mathrm{O}$.

анизотропией магнитного экранирования, а сдвиги сигналов концевых атомов фтора — в более слабом поле, и будут иметь высокую анизотропию экранирования [23].

В спектре ЯМР ВМУ ${ }^{19} \mathrm{~F} \quad \gamma-\mathrm{NH}_{4} \mathrm{ZrF}_{5}$ содержатся сигналы с ХC 22.9, -8.9 и -39.5 ppm, интегральные интенсивности которых, определенные с учетом боковых линий от вращения, относятся как 50:32:18 (рис. 3,a). Первые два сигнала соответствуют позициям атомов фтора со значительной анизотропией экранирования. Третий сигнал $(\mathrm{XC}-39.5$ ppm) отвечает фтору с небольшими значениями анизотропии экранирования и константы диполь-дипольного взаимодействия, благодаря чему он выглядит более интенсивным. На каждый атом циркония в структуре $\mathrm{NH}_{4} \mathrm{ZrF}_{5}$ приходится два концевых атома фтора на коротком $(\sim 2.0 \AA)$ расстоянии $\left(\mathrm{F}_{\mathrm{a}}\right)$, два атома фтора, связывающие атомы циркония по вершине $\left(\mathrm{F}_{\mathrm{b}}\right)$ несимметричной мостиковой связью (более короткая связь имеет длину 2.06-2.07 $\AA$ ), один атом фтора $\left(\mathrm{F}_{\mathrm{c}}\right)$, участвующий в объединении полиэдров циркония по ребру через связи не короче $2.17 \AA$. Принимая во внимание наложение боковых линий и возможную ошиб- 

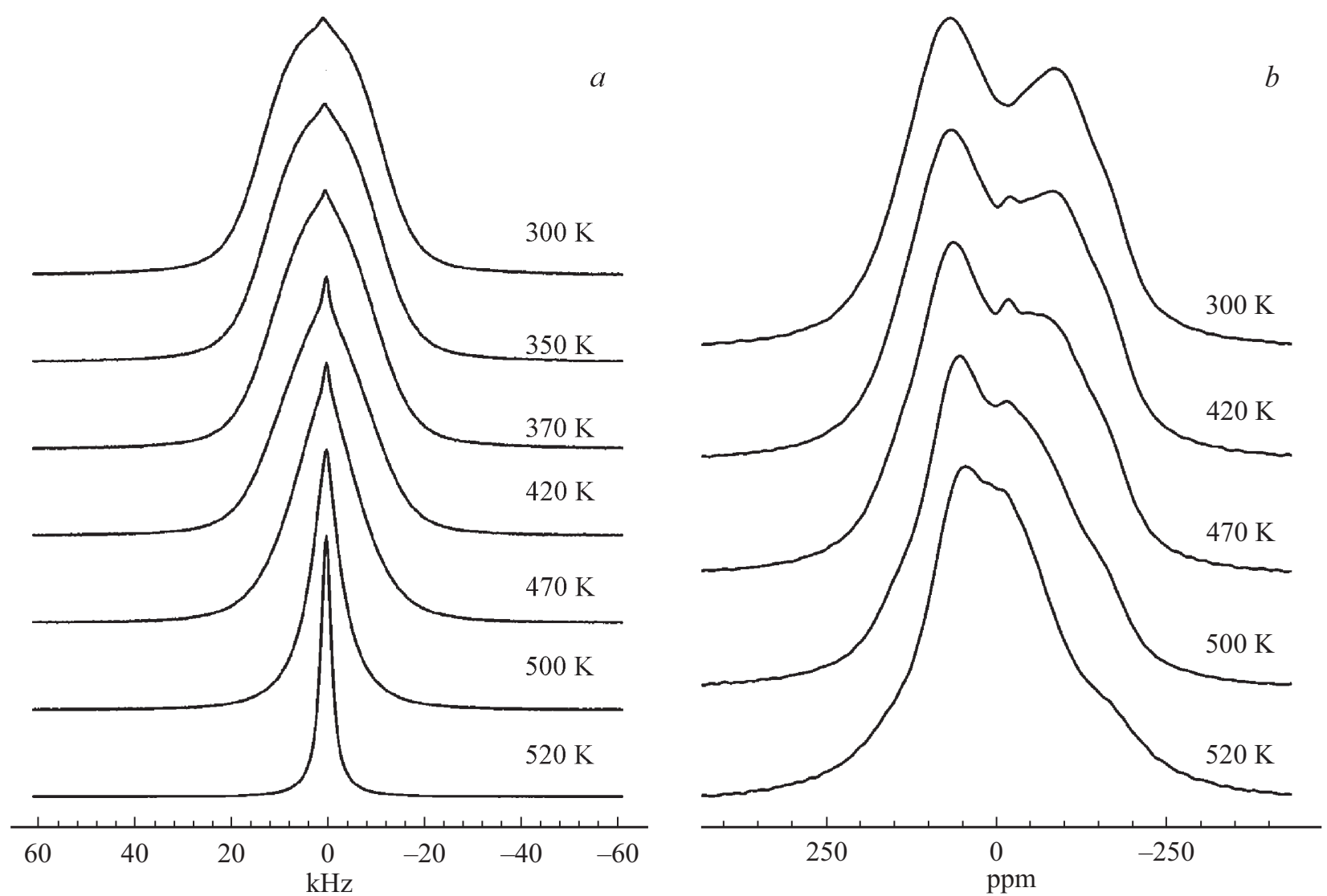

Рис. 4. Спектры ЯМР ${ }^{1} \mathrm{H}(a)$ и ${ }^{19} \mathrm{~F}(b)$ соединения $\gamma-\mathrm{NH}_{4} \mathrm{ZrF}_{5}$.

ку определения интегральных интенсивностей в 10\%, можно отнести сигналы, наблюдаемые в направлении возрастания магнитного поля, к атомам фтора $\mathrm{F}_{\mathrm{a}}, \mathrm{F}_{\mathrm{b}}$ и $\mathrm{F}_{\mathrm{c}}$ соответственно.

Спектры ЯМР ВМУ ${ }^{19} \mathrm{~F} \mathrm{NH}_{4} \mathrm{ZrF}_{5} \cdot 0.75 \mathrm{H}_{2} \mathrm{O}$ содержат не менее семи сигналов, объединенных в две группы (рис. $3, b$ ). С учетом структурных данных можно предположить, что сигналы концевых атомов расположены в области слабого магнитного поля (ХC 28.6-20.1 ppm), а сигналы от мостиковых атомов типа $\mathrm{Zr}\langle 2 \mathrm{~F}\rangle \mathrm{Zr}$, связывающих полиэдры $\left[\mathrm{ZrF}_{8}\right]$ и $\left[\mathrm{ZrF}_{7} \mathrm{OH}_{2}\right]$ между собой, в области сильного поля. Значительный разброс длин мостиковых связей приводит к набору сигналов в спектре соединения, а большая суммарная интенсивность сигналов в сильном поле (ХC $-18.0--58.4 \mathrm{ppm})$ соответствует тому, что длинные связи $\mathrm{Zr}-\mathrm{F}_{\mathrm{M}}$ преобладают в структуре соединения.

Спектры ЯМР ${ }^{1} \mathrm{H} \mathrm{NH} \mathrm{NH}_{4} \mathrm{ZF}_{5}$ при температуре ниже $370 \mathrm{~K}$ имеют форму функции Абрагама, характерную для реориентирующихся ионов аммония (рис. 4,a). Спектры содержат также узкую компоненту, площадь которой не превышает одного процента. Полуширина спектров составляет $25 \mathrm{kHz}$. Выше $370 \mathrm{~K}$ спектры испытывают сужение вследствие начала локальных движений ионов аммония. Трансформация спектров продолжается до максимально достигнутой в эксперименте темпера- туры $520 \mathrm{~K}$. Параметры спектра при этой температуре $\left(\Delta v_{1 / 2}=3 \mathrm{kHz}\right.$, лоренцева форма) указывают на наличие трансляционной диффузии ионов аммония. С учетом строения соединения катионная диффузия является ожидаемой, однако широкий температурный диапазон сужения линии ЯМР (более $100 \mathrm{~K}$ ) свидетельствует о том, что развитие диффузии включает несколько этапов.

Спектры ЯМР ${ }^{1} \mathrm{H}$ гидратов могут быть разложены на компоненту пейковской формы, соответствующую молекулам воды, и центральную компоненту, относящуюся к ионам аммония. Трансляционные движения ионов аммония, реориентационные движения молекул воды или протонная диффузия, согласно данным ЯМР, в температурном интервале $150-320 \mathrm{~K}$ отсутствуют.

Статические спектры ЯМР ${ }^{19} \mathrm{~F} \quad \mathrm{NH}_{4} \mathrm{ZrF}_{5} \cdot n \mathrm{H}_{2} \mathrm{O}$ $(n=0.75,1)$ (рис. $5, a, b)$ асимметричны и имеют достаточно большую полуширину $(80-100 \mathrm{kHz})$. Форма спектров определяется анизотропией магнитного экранирования, диполь-дипольными взаимодействиями ядер фтора между собой и с протонами ионов аммония и молекул воды, неэквивалентностью позиций атомов фтора. Положение центра тяжести спектров в зависимости от $n$ несколько изменяется и составляет $0,-8$ и $-14 \mathrm{ppm}$ для $n=0,0.75$ и 1 соответственно. Тенденция к сдвигу сигналов ЯМР гидратов в сильное поле находится в соответствии с тем, что при координации цирконием 


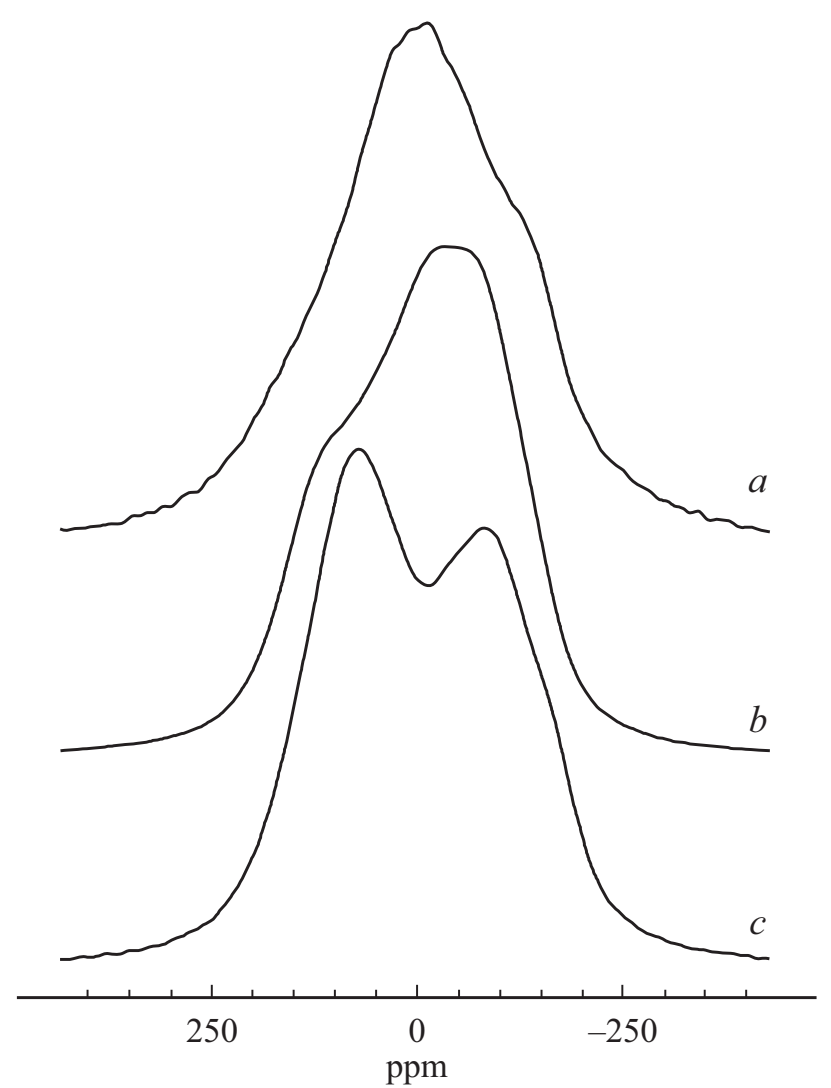

Рис. 5. Спектры ЯМР ${ }^{19} \mathrm{~F}$ : (a) $\mathrm{NH}_{4} \mathrm{ZrF}_{5} \cdot \mathrm{H}_{2} \mathrm{O}$, (b) $\mathrm{NH}_{4} \mathrm{ZrF}_{5} \cdot 0.75 \mathrm{H}_{2} \mathrm{O}$, (c) $\gamma-\mathrm{NH}_{4} \mathrm{ZrF}_{5}$ при температуре $300 \mathrm{~K}$.

молекулы воды связь $\mathrm{Zr}-\mathrm{F}$, находящаяся в транс-положении, становится более длинной. В форме статических спектров рассматриваемых гидратов имеются заметные различия. Можно отметить „перевернутую“ форму спектра $\mathrm{NH}_{4} \mathrm{ZrF}_{5} \cdot 0.75 \mathrm{H}_{2} \mathrm{O}$ (более интенсивное плечо находится в сильном магнитном поле), нехарактерную для фторидоцирконатов. Дублетная форма статических спектров $\mathrm{NH}_{4} \mathrm{ZrF}_{5}$ (рис. 5,c), вероятно, объясняется особенностями строения соединения, при котором величина диполь-дипольных взаимодействий атомов фтора соседних слоев $(r(\mathrm{~F}-\mathrm{F})=2.978 \AA)$ друг с другом и с протонами ионов аммония $(r(\mathrm{~F}-\mathrm{N})=2.772 \AA)$ находятся в определенном соотношении со сдвигом, обусловленным анизотропией химического экранирования (кросссингулярные эффекты [24]).

При нагревании $\mathrm{NH}_{4} \mathrm{ZrF}_{5}$ выше $420 \mathrm{~K}$ начинается сужение линии ЯМР ${ }^{19} \mathrm{~F}$, которое, вероятно, главным образом связано с усреднением диполь-дипольных взаимодействий ${ }^{19} \mathrm{~F}-{ }^{1} \mathrm{H}$ вследствие начала диффузии ионов аммония, но может быть частично обусловленным и локальными движениями ионов фтора. В ходе трансформации спектра дублетная форма линии становится однокомпонентной (рис. $4, b$ ). Форма и ширина спектров ЯМР ${ }^{19} \mathrm{~F} \mathrm{NH}_{4} \mathrm{ZrF}_{5} \cdot 0.75 \mathrm{H}_{2} \mathrm{O}$ и $\mathrm{NH}_{4} \mathrm{ZrF}_{5} \cdot \mathrm{H}_{2} \mathrm{O}$ практи- чески не меняются с температурой до начала разложения соединений (360 и $350 \mathrm{~K}$ соответственно).

\section{Перестройка структуры при переходе $\mathrm{NH}_{4} \mathrm{ZrF}_{5} \cdot n \mathrm{H}_{2} \mathrm{O}$ в $\mathrm{NH}_{4} \mathrm{ZrF}_{5}$}

В результате дегидратации $\mathrm{NH}_{4} \mathrm{ZrF}_{5} \cdot \mathrm{H}_{2} \mathrm{O}$ при удалении молекул $\mathrm{H}_{2} \mathrm{O}$ из полиэдров $\left[\mathrm{ZrF}_{7} \mathrm{H}_{2} \mathrm{O}\right]$ можно предположить переходное состояние анионного комплекса, состоящее из цепи семикоординированных КП $\mathrm{Zr}$, объединенных реберной связью. Примеры кристаллических структур пентафторидоцирконатов с подобным цепочечным строением комплексного аниона в настоящее время известны. Они характерны для соединений, в которых внешнесферными являются протонированные органические катионы [25] либо алкиламмонийкатионы [26,27]. В пентафторидоцирконате аммония в отличие от перечисленных соединений катион оказывает бо́льшее поляризующее действие на анион, что сказывается на мотиве строения последнего. Вследствие энергетической неустойчивости цепочечной структуры с КЧ Zr 7 [28] логично предположить ее переход в слоистую с повышением КЧ Zr и образованием F-мостиковой реберной связи между $\mathrm{Zr}$-полиэдрами соседних цепей, соединенных в кристаллогидрате ВС. Объединение $\mathrm{Zr}$-цепей происходит с образованием слоев, параллельных плоскости (110). В слое биполиэдры поочередно объединяются реберной связью с Zr-полиэдром из нижележащей цепи и с Zr-полиэдром из вышележащей цепи. Реберная связь между $\mathrm{Zr}$-полиэдрами исходной структуры преобразуется в структуре $\mathrm{NH}_{4} \mathrm{ZrF}_{5}$ в вершинную (рис. 1, $d$, стрелка). Угол $\mathrm{Zr}-\mathrm{Zr}-\mathrm{Zr}$ вдоль этих вершинных связей $\left(142.10^{\circ}\right)$ близок к углу в цепочечной структуре кристаллогидрата $\left(139.10^{\circ}\right)$. В итоге формируются слои из гексаядерных фрагментов, в которых можно выделить один четырехчленный и два трехчленных металлоциклов. Таким образом, в результате трансформации организуется новая поперечная реберная связь, сшивающая цепи в единый слой, так что каждый КП $\mathrm{Zr}$ связан с пятью другими КП $\mathrm{Zr}$ одной реберной и четырьмя вершинными мостиковыми связями.

Трансформация слоистой структуры $\mathrm{NH}_{4} \mathrm{ZrF}_{5} \cdot 0.75 \mathrm{H}_{2} \mathrm{O}$ при переходе в $\mathrm{NH}_{4} \mathrm{ZrF}_{5}$ также обусловлена снижением КЧ Zr в части КП, образующихся при удалении координированных молекул воды. Среди исследованных кристаллических структур пентафторидоцирконатов существует пример структуры, в которой полимерные слои образованы из КП $\left[\mathrm{ZrF}_{7}\right]$ и $\left[\mathrm{ZrF}_{8}\right]$, связанных посредством общих ребер. Это кристаллическая структура гидрата с протонированным органическим катионом состава $\left[\operatorname{dapH}_{2}\left(\mathrm{Zr}_{2} \mathrm{~F}_{10}\right) \cdot \mathrm{H}_{2} \mathrm{O}\right.$ (dap-бис-(1-3)-диаминопропан [29]. Структура стабилизируется атомами водорода групп $\mathrm{NH}_{3}$ и молекул $\mathrm{H}_{2} \mathrm{O}$. В отсутствие молекул $\mathrm{H}_{2} \mathrm{O}$ стабилизация образующейся структуры при переходе от $\mathrm{NH}_{4} \mathrm{ZrF}_{5} \cdot 0.75 \mathrm{H}_{2} \mathrm{O}$ к $\mathrm{NH}_{4} \mathrm{ZrF}_{5}$ достигается путем увеличения КЧ Zr и перераспределения мостиковых 
связей. В исходной структуре $\mathrm{NH}_{4} \mathrm{ZrF}_{5} \cdot 0.75 \mathrm{H}_{2} \mathrm{O}$ можно выделить участки уже готовых для будущей структуры фрагментов в виде цепей, состоящих из КП $\left[\mathrm{ZrF}_{8}\right]$.

Таким образом, в реакциях дегидратации (гидратации) $\mathrm{NH}_{4} \mathrm{ZrF}_{5} \quad n \mathrm{H}_{2} \mathrm{O} \leftrightarrow \mathrm{NH}_{4} \mathrm{ZrF}_{5}$ проявляется конкуренция мостиковых атомов фтора и молекул воды за координационную сферу центрального атома, так как указанные лиганды близки по электронодонорным свойствам.

Из совокупности полученных данных следует, что структурные трансформации при термических превращениях $\mathrm{NH}_{4} \mathrm{ZrF}_{5} \cdot n \mathrm{H}_{2} \mathrm{O}$ и $\left(\mathrm{NH}_{4}\right)_{2} \mathrm{ZrF}_{6}$ в $\mathrm{NH}_{4} \mathrm{ZrF}_{5}$ определяются степенью „структурной подготовленности“ исходной и новообразованной фаз и связаны со стабилизацией структуры, которая реализуется за счет повышения КЧ $\mathrm{Zr}$ в слоистой структуре пентафторидоцирконата аммония.

\section{Выводы}

Методами ИК, КР, ЯМР $\left({ }^{1} \mathrm{H},{ }^{19} \mathrm{~F}\right.$, включая ВМУ $\left.{ }^{19} \mathrm{~F}\right)$, ТГ-ДТА исследовано влияние гидратного числа на изменение строения, термических свойств и характер ионной (молекулярной) подвижности в кристаллогидратах $\mathrm{NH}_{4} \mathrm{ZrF}_{5} \cdot \mathrm{H}_{2} \mathrm{O}, \mathrm{NH}_{4} \mathrm{ZrF}_{5} \cdot 0.75 \mathrm{H}_{2} \mathrm{O}$ и $\mathrm{NH}_{4} \mathrm{ZrF}_{5}$. Данными ИК, КР-спектроскопии подтверждены отличительные структурные особенности кристаллогидратов: строение анионов, состояние молекул воды, прочность ВС $\mathrm{O}-\mathrm{H} \cdots \mathrm{F}, \mathrm{N}-\mathrm{H} \cdots \mathrm{F}$. Методом ЯМР ВМУ ${ }^{19} \mathrm{~F}$ определены изотропные ХC магнитно-неэквивалентных позиций и соотнесены с кристаллическими структурами исследованных соединений. Установлено, что с отщеплением молекул воды из $\mathrm{NH}_{4} \mathrm{ZrF}_{5} \cdot \mathrm{H}_{2} \mathrm{O}$ и $\mathrm{NH}_{4} \mathrm{ZrF}_{5} \cdot 0.75 \mathrm{H}_{2} \mathrm{O}$ происходит трансформация цепочечной или слоистой структур с повышением степени полимеризации, сопровождающаяся увеличением числа мостиковых связей. По данным ЯМР ${ }^{1} \mathrm{H}$ диффузия катионов $\mathrm{NH}_{4}^{+}$имеет место только в $\mathrm{NH}_{4} \mathrm{ZrF}_{5}$ в интервале температур $370-520 \mathrm{~K}$.

Работа была выполнена при финансовой поддержке Министерства образования и науки Российской Федерации (Федеральное агентство научных организаций, проект № 0265-2018-0001).

\section{Список литературы}

[1] Кавун В.Я., Сергиенко В.И. Диффузионная подвижность и ионный транспорт в кристаллических и аморфных фторидах элементов IV группы и сурьмы (III). Владивосток: Дальнаука, 2004. 298 с.

[2] Кавун В.Я., Ткаченко И.А., Диденко Н.А., Слободюк А.Б., Сергиенко В.И. // Журн. неорг. химии. 2010. Т. 55. № 8. C. 1253.

[3] Кавун В.Я., Сергиенко В.И., Чернышов Б.Н., Диденко Н.А., Бакеева Н.Г., Игнатьева Л.Н. // Журн. неорг. химии. 1991. Т. 36. № 4. С. 1004.

[4] Gaument V., Latouche C., Avignant D., Dupuis J. // Solid State Ionics. 1994. V. 74. P. 29.
[5] Gerasimenko A.V., Gaivoronskaya K.A., Slobodyuk A.B., Didenko N.A. // Z. Anorg. Allg. Chem. 2017. B. 643. S. 1785.

[6] Диденко Н.А., Гайворонская К.А., Войт Е.И., Герасименко А.В., Кавун В.Я. // Журн. неорг. химии. 2010. Т. 55. № 9. C. 1420 .

[7] Войт Е.И., Диденко Н.А., Гайворонская К.А., Герасименко А.В. // Опт. и спектр. 2016. Т. 121. № 1. С. 72.

[8] Гайворонская К.А., Герасименко А.В., Диденко Н.А., Слободюк А.В., Кавун В.Я. // Журн. неорг. химии. 2013. T. 58. № 2. C. 226.

[9] Годнева М.М., Мотов Д.Л. Химия подгруппы титана. Сульфаты, фториды, фторосульфаты из неводных сред. М.: Наука, 2006. 302 с.

[10] Тананаев И.В., Гузеева Л.С., Петров К.И. // Изв. СО АН СССР. Серия хим. наук. 1968. Т. 1. № 2. С. 103.

[11] Hull H., Turnbull A.G. // J. Inorg. Nucl. Chem. 1967. V. 29. P. 2903.

[12] Smith P.W., Stoessiger R., Turnbull A.G. // J. Chem. Soc. (A). 1968. P. 3013.

[13] Войт Е.И., Диденко Н.В., Гайворонская К.А. // Опт. и спектр. 2018. Т. 124. № 3. С. 333.

[14] Буквеикий Б.В., Герасименко А.В., Давидович Р.Л. // Коорд. химия. 1991. Т. 17. № 1. С. 35.

[15] Zalkin A., Eimerl D., Velsko S.P. // Acta Crystallogr. 1988. V. C44. N 12. P. 2050

[16] Ткачев В.В, Удовенко А.А., Давидович Р.Л., Атовмян Л.О. // Коорд. химия. 1991. Т. 17. № 12. С. 1635.

[17] Гайворонскал К.А., Герасименко А.В., Диденко Н.А. // Журн. структ. химии. 2018. Т. 59. № 3. С. 634.

[18] Герасименко А.В., Кавун В.Я., Сергиенко В.И., Антохина Т.Ф. // Коорд. химия. 1999. Т. 25. № 8. С. 604.

[19] Буквецкий Б.В., Герасименко А.В., Давидович Р.Л. // Коорд. химия. 1991. Т. 17. № 1. С. 35.

[20] Ткачев В.В., Давидович Р.Л., Атовмян Л.О. // Коорд. химия. 1991. Т. 17. № 11. С. 1485.

[21] Gao Y., Guery J., Le Bail A., Jacoboni C. // J. Sol. St. Chem. 1992. V. 98. N 1. P. 11.

[22] Avignant D., Mansouri I., Chevalier R., Cousseins J.C. // J. Sol. St. Chem. 1981. V. 38. N 1. P. 121.

[23] Youngman R.E., Sen S. // Sol. St. NMR. 2005. V. 27. P. 77.

[24] Зеер Э.П., Зобов В.Е., Фалалеев О.В. Новые эффекты в ЯМР поликристаллов. Новосибирск: Наука, 1991. 184 с.

[25] Буквецкий Б.В., Герасименко А.В., Давидович Р.Л. // Коорд. химия. 1992. Т. 18. № 6. С. 576.

[26] Ross II C.R., Bauer M.R., Nielson R.M., Abrahams S.C. // Acta Crystallogr. 2002. B. 58. N 5. P. 841.

[27] Герасименко А.В., Давидович Р.Л. // Вестник ДВО РАН. 2006. № 5. C. 17.

[28] Войт Е.И., Войт А.В., Герасименко А.В., Сергиенко В.И. // Журн. структ. химии. 2000. Т. 41. № 2. С. 255.

[29] Ben Ali A., Body M., Leblanc M., Maisonneuve V. // Sol. St. Sci. 2011. V. 13. N 2. P. 394. 